\title{
Prognostic influence of witness/victim experiences and PTSD-specific symptoms on working and educational capacity: a comparison between two groups of individuals post-trauma
}

\author{
Helge H Müller ${ }^{1 * \dagger}$, Sebastian Moeller ${ }^{2 \dagger}$, York Hilger ${ }^{3}$ and Wolfgang Sperling ${ }^{1}$
}

\begin{abstract}
Background: Trauma exposure depends of the type of trauma and can result in the development of posttraumatic stress disorder (PTSD). The type of traumatization (such as Holocaust experiences and other sources of trauma) and specific symptoms of PTSD have influences on the outcome, and specific symptoms of PTSD influence personal and professional outcomes. Another factor is the role of the victim in their traumatization. Some patients are actively traumatized through being victims of torture, while others are passively traumatized by witnessing the traumatization of others.
\end{abstract}

Methods: We compared two groups of victim/witness trauma sufferers (PTSD vs. Holocaust-experience PTSD (HE-PTSD)) with regard to PTSD symptoms, educational and working capacity, and functional outcome parameters.

Results: HE-PTSD survivors with victim/witness trauma experience showed substantially more specific PTSD symptoms and higher symptom-specific intensities but had high social function and education levels. The intensity and type of intrusive memories and sociodemographic factors do not seem to have a prognostic influence on working or educational outcomes.

Conclusions: Identifying the combined victim/witness experience seems to play an important prognostic role in the assessment of PTSD victims. Further studies should consider these findings within other specific traumatization groups.

Keywords: PTSD symptoms, Educational/working capacity, Prognostic outcome

\section{Introduction and background}

Exposure to a traumatic event or psychological stress can result in posttraumatic stress disorder (PTSD). PTSD is classified based on five parameters: a person's exposure to a traumatic event, re-experiencing the event with intrusive memories that are typically reported as "flash-back experiences" by the individual, persistent avoidance of trauma reminders, reduced emotional response after trauma, and persistent symptoms of increased arousal. Education and

\footnotetext{
* Correspondence: helge.mueller@uk-erlangen.de

${ }^{\dagger}$ Equal contributors

'Department of Psychiatry and Psychotherapy, Friedrich-Alexander University of Erlangen-Nuremberg, Schwabachanlage 6, D-91054 Erlangen, Germany Full list of author information is available at the end of the article
}

working abilities and social functioning are impaired in PTSD traumatized persons [1,2].

Moreover, in PTSD, resilience structures are diminished [3]. Resilience is defined as a person's ability to recover quickly from illness, i.e., the quality that enables something to resume its original shape or position after being bent, stretched, or compressed, and this capacity influences individual psychological elasticity. Resilience is indirectly associated with social functioning and outcome, e.g., educational ability, and thus influences working capacity [4-7].

Patients who have experienced trauma can be divided into groups depending on the type of trauma. One subgroup of PTSD patients is Holocaust survivors (HE-PTSD). Traumatization during the Holocaust was formative for 
these individuals' personality and resilience structures $[6,8,9]$. The main stress factors during the Holocaust experience were early separation from parents, confrontation with the deaths of relatives, physical impairment, and torture [9-11]. Thus, Holocaust survivors suffer from somatic diseases caused by traumatization, and they also experience PTSD-specific symptoms with affective and/or dissociative impairments $[1,12,13]$.

HE-PTSD and PTSD have never been analyzed separately and have not been systematically compared with each other in the context of educational and working capacity outcomes.

\section{Methods}

The comparative study was approved by the local ethical committee and then conducted with 80 HE-PTSD survivors (47 female, 33 male, mean age 76.20 years \pm 6.49 ) and 40 PTSD victims (14 female, 26 male, mean age 46.90 years \pm 10.42 ). All participants gave written consent to participate.

HE-PTSD and PTSD were categorized according to the DSM-IV-R criteria. When evaluating the files, sociodemographic data and sociodemographic outcome parameters, such as gender, age, and school education (years), quality of school education, and years in job were evaluated. Additionally, the type of traumatization (witness or victim); occurrence of flashback-experiences, which were classified by the type of intrusive memory (visual, acoustic, or other); and their intensity ( $>2 /$ day, $>2 /$ week, or $>2$ / month), were analyzed. All participants provided a structured clinical interview to examine (HE-) PTSD-specific symptoms.

For data analysis, we used the statistical program SPSS 22.0, (IBM Corp., Armonk, NY). We tested the data for normal distribution using the Kolmogorov-Smirnov test. For dichotomous variables, the chi-square test or Fisher's exact test was used, as appropriate. For normally distributed data, variance testing was conducted using Levene's test. Normally distributed data were compared using $t$ tests for unpaired samples. Non-normally distributed data were compared using the Mann-Whitney $U$ test, and group differences (e.g., age, gender, and sociodemographic parameters) were tested for significant group bias. For significant group differences, Fisher's least significant difference (LSD) post hoc test was administered. Significance was assumed, consequently, at $p<0.05$.

\section{Results}

Within the group of Holocaust survivors, all patients $(100 \%)$ were both victims and witnesses of traumatization. Thirty-four PTSD patients $(85 \%)$ were only victims $(p<0.001), 5(2 \%)$ patients were only witnesses of violent acts against others, and only one patient $(0.4 \%)$ fulfilled both the victim and witness criteria.
Forty-seven patients $(58.8 \%)$ of the HE-PTSD group and 31 (77.5\%) of the PTSD group had multiple flashbacks or intrusive memory experiences per day. Furthermore, 23 patients $(28.8 \%)$ in the HE-PTSD group had visual and acoustic intrusive memory experiences, compared to $38(15.2 \%)$ in the PTSD group $(p<0.001)$.

Thirty-seven participants (46.3\%) in the HE-PTSD group and 31 participants (77.5\%) in the PTSD group had completed basic or primary school; 33 (41.3\%) HE-PTSD patients and 5 (12.5\%) PTSD-patients had completed high school. Ten (12.5\%) HE-PTSD patients and 4 (10\%) PTSD-patients obtained university entrance diplomas. There were no significant differences with regard to years of employment between the two groups $(p=0.273$ ), (see Table 1).

Table 1 Symptoms, traumatization category, sociodemographic items, and education levels of HE-PTSD and PTSD patients (significance set at <0.05)

\begin{tabular}{|c|c|c|c|}
\hline Parameters & $\begin{array}{l}\text { HE-PTSD group } \\
(n=80)\end{array}$ & $\begin{array}{l}\text { PTSD group } \\
(n=40)\end{array}$ & $P$ value \\
\hline Age [years] & $76.2 \pm 6.5$ & $46.9 \pm 10.4$ & $<0.001$ \\
\hline Sex [female/male] & $\begin{array}{l}47(58.8 \%) / \\
33(41.3 \%)\end{array}$ & $\begin{array}{l}14(35.0 \%) / \\
26(65 \%)\end{array}$ & 0.020 \\
\hline \multicolumn{4}{|l|}{ Traumatization category } \\
\hline Victim only & 0 & 34 & \\
\hline Witness only & 0 & 5 & \\
\hline Victim and witness & 80 & 1 & $<0.001$ \\
\hline \multicolumn{4}{|l|}{ Quality of intrusive memories } \\
\hline Visual & 52 & 38 & \\
\hline Acoustic & 5 & 0 & \\
\hline Visual and acoustic & 23 & 0 & \\
\hline Other (e.g., olfactory) & 0 & 2 & $<0.001$ \\
\hline \multicolumn{4}{|l|}{ Symptom intensity } \\
\hline$>2$ /day & 47 & 31 & \\
\hline$>2 /$ week & 26 & 8 & \\
\hline$>2$ /month & 7 & 1 & 0.039 \\
\hline \multicolumn{4}{|l|}{ School education level } \\
\hline Basic primary school & 37 & 31 & \\
\hline \multicolumn{4}{|l|}{ Secondary modern school } \\
\hline Junior high school & 33 & 5 & \\
\hline $\begin{array}{l}\text { University-entrance } \\
\text { diploma }\end{array}$ & 10 & 4 & 0.002 \\
\hline \multicolumn{4}{|l|}{ Professional qualification } \\
\hline Labor & 40 & 36 & \\
\hline Mid-level administration & 5 & 1 & \\
\hline Administration & 35 & 3 & $<0.001$ \\
\hline \multicolumn{4}{|l|}{ Years in job } \\
\hline$[$ Mean \pm SD $]$ & $19.64 \pm 19.57$ & $23.83 \pm 9.84$ & 0.273 \\
\hline
\end{tabular}




\section{Discussion and conclusions}

Our findings suggest that HE-PTSD survivors have a higher professional qualification level than PTSD patients. One important aspect of PTSD outcome assessment is to consider the symptom complex, which is characterized by the multifactorial influence of traumatization [14-16]. Another important point in the understanding of PTSD symptoms and the associated impairments on work and education capacity is the role of the person within the traumatization. HE-PTSD survivors with high rates of victim and witness trauma experience showed substantially more specific PTSD symptoms and higher rates and different types of symptomspecific intensities. HE-PTSD survivors often show surprisingly high social function and education levels [17], which is also a notable finding in our study. The experience of double traumatization in HE-PTSD, as both witness and victim, is highly significantly associated with higher education levels as a social outcome parameter but not with years of employment compared to PTSD patients.

The other factors examined, such as the intensity and type of reported intrusive memories and sociodemographic factors, such as gender and age, do not seem to have a prognostic influence on work or educational outcomes. It remains unclear whether passive experiences compared to more active victim-witness traumatization are responsible for reduced social functioning and working capacity.

It is a limitation of our examination that both the HE-PTSD and PTSD groups are quite heterogeneous, especially concerning mean age and gender. Thus, the influence of age- and gender-related bias cannot completely be eliminated, although the sample group was controlled by LSD post hoc testing, which is the suitable test in random samples of that size. The most remarkable finding is that identification of the combined victim/witness experience seems to play an important prognostic role in the assessment of PTSD victims.

The question arises which other prognostic influence factors, such as medical and psychological treatment, influence the educational and social function levels of PTSD victims and affect personal resilience structures.

Our study is limited by the absence of an extended examination of these potentially important factors in the multifactorial PTSD complex and by differences in the age and gender proportions. It is a natural fact that control groups with equal median ages are difficult to find. There are also more women who survived torture and prosecution within the holocaust experience [18], especially in our sample group. Moreover, we did not assess the time-point of traumatization within the group of PTSD patients.
Further studies with larger participant groups are needed to address these points. Other groups that have experienced other types of trauma should be examined in the context of victim and witness experiences.

\section{Competing interests}

The authors declare that they have no competing interests.

\section{Authors' contributions}

All authors participated in drafting and revising the manuscript, data analysis, and interpretation of data, and all contributed substantially to the acquisition of data and ensured that questions related to the accuracy of the work were appropriately resolved. HHM and SM wrote the manuscript. HHM, SM, and WS participated in the design of the study. YH performed statistical analysis, critically revised the manuscript, and made a substantial contribution to the acquisition of data (all clinical data). All authors provided final approval of the version to be published. All authors have read and approved the final manuscript.

\section{Acknowledgements}

We acknowledge support by the Deutsche Forschungsgemeinschaft and Friedrich-Alexander-Universität Erlangen-Nürnberg (FAU) within the funding programme Open Access Publishing.

\section{Author details}

${ }^{1}$ Department of Psychiatry and Psychotherapy, Friedrich-Alexander University of Erlangen-Nuremberg, Schwabachanlage 6, D-91054 Erlangen, Germany. ${ }^{2}$ Department of Neurology, Friedrich-Alexander University of Erlangen-Nuremberg, Erlangen, Germany. ${ }^{3}$ Institution of Statistical Analysis, Freiburg im Breisgau, Germany.

Received: 18 August 2014 Accepted: 27 January 2015

Published online: 12 February 2015

\section{References}

1. Biermann T, Sperling W, Muller H, Schutz P, Kornhuber J, Reulbach U. [Long-term analysis of disability pensions in survivors of the Holocaust: somatic and psychiatric diagnoses]. Fortschr Neurol Psychiatr. 2010;78:715-21.

2. Zoellner LA, Bedard-Gilligan MA, Jun JJ, Marks LH, Garcia NM. The Evolving Construct of Posttraumatic Stress Disorder (PTSD): DSM-5 Criteria Changes and Legal Implications. Psychol Inj Law. 2013;6:277-89.

3. Burnett Jr HJ, Helm Jr HW. Relationship between posttraumatic stress disorder, resilience, and religious orientation and practices among university student earthquake survivors in Haiti. Int J Emerg Ment Health. 2013;15:97-104.

4. Richardson GE. The metatheory of resilience and resiliency. J Clin Psychol. 2002;58:307-21.

5. Karstoft Kl, Armour C, Elklit A, Solomon Z. Long-term trajectories of posttraumatic stress disorder in veterans: the role of social resources. J Clin Psychiatry. 2013;74:e1163-1168.

6. Zerach G, Solomon Z, Cohen A, Ein-Dor T. PTSD, resilience and posttraumatic growth among ex-prisoners of war and combat veterans. Isr J Psychiatry Relat Sci. 2013;50:91-8.

7. Skeffington PM, Rees CS, Kane R. The primary prevention of PTSD: a systematic review. J Trauma Dissociation. 2013;14:404-22.

8. Maercker A, Michael T, Fehm L, Becker ES, Margraf J. Age of traumatisation as a predictor of post-traumatic stress disorder or major depression in young women. Br J Psychiatry. 2004;184:482-7.

9. Bunk D, Eggers C. [The significance of psychodynamic relationship factors for psychopathogenesis in childhood Nazi persecution]. Fortschr Neurol Psychiatr. 1993;61:38-45.

10. Fossion $P$, Leys $C$, Kempenaers $C$, Braun $S$, Verbanck $P$, Linkowski $P$. Depression, anxiety and loss of resilience after multiple traumas: an illustration of a mediated moderation model of sensitization in a group of children who survived the Nazi Holocaust. J Affect Disord. 2013;151(3):973-9.

11. Dekel S, Mandl C, Solomon Z. Is the Holocaust implicated in posttraumatic growth in second-generation Holocaust survivors? A prospective study. J Trauma Stress. 2013;26:530-3. 
12. Muller H, Seifert F, Asemann R, Schutz P, Maler JM, Sperling W. Persecutioninduced reduction in earning capacity of Holocaust victims: influence of psychiatric and somatic aspects. Psychopathology. 2011;44:225-9.

13. Sperling W, Kreil SK, Biermann T. Posttraumatic stress disorder and dementia in Holocaust survivors. J Nerv Ment Dis. 2011;199:196-8.

14. Jonkman CS, Verlinden E, Bolle EA, Boer F, Lindauer RJ. Traumatic stress symptomatology after child maltreatment and single traumatic events: different profiles. J Trauma Stress. 2013;26:225-32.

15. Klaric M, Franciskovic T, Obrdalj EC, Petric D, Britvic D, Zovko N. Psychiatric and health impact of primary and secondary traumatization in wives of veterans with posttraumatic stress disorder. Psychiatr Danub. 2012;24:280-6.

16. Collimore KC, Carleton RN, Hofmann SG, Asmundson GJ. Posttraumatic stress and social anxiety: the interaction of traumatic events and interpersonal fears. Depress Anxiety. 2010;27:1017-26.

17. Barel E, Van IMH, Sagi-Schwartz A, Bakermans-Kranenburg MJ. Surviving the Holocaust: a meta-analysis of the long-term sequelae of a genocide. Psychol Bull. 2010;136:677-98

18. Aviad-Wilchek Y, Cohenca-Shiby D, Sasson Y. The effects of the survival characteristics of parent holocaust survivors on offsprings' anxiety and depression symptoms. Isr J Psychiatry Relat Sci. 2013;50:210-6.

\section{Submit your next manuscript to BioMed Central and take full advantage of:}

- Convenient online submission

- Thorough peer review

- No space constraints or color figure charges

- Immediate publication on acceptance

- Inclusion in PubMed, CAS, Scopus and Google Scholar

- Research which is freely available for redistribution 